\title{
ISO 15016:2015-Based Method for Estimating the Fuel Oil Consumption of a Ship
}

\author{
Ki-Su Kim $『$ and Myung-Il Roh * \\ Department of the Naval Architecture and Ocean Engineering, Seoul National University, Seoul 08826, Korea; \\ kisu2511@snu.ac.kr \\ * Correspondence: miroh@snu.ac.kr
}

Received: 18 September 2020; Accepted: 10 October 2020; Published: 12 October 2020

check for updates

\begin{abstract}
Recently, interest in the design and construction of smart ships has been widely increasing. Optimal route planning is a widely studied essential aspect of smart ship technology. Planning an optimal route requires an accurate estimation of the fuel oil consumption of a ship. Various studies have suggested methods for theoretically estimating the fuel oil consumption. However, the calculation methodology and accuracy are different for each method. In addition, in commercial software, a statistical model based mainly on operating data has been used. Therefore, in this study, we propose a method based on ISO 15016:2015 for estimating the fuel oil consumption of a ship by improving the ISO 15016:2002 method-which has been predominantly used in existing studies. Moreover, the accuracy of the proposed method is examined by comparing it with a gray box model based on operating data. The results confirm that the proposed method can be used for estimating the fuel oil consumption of a ship.
\end{abstract}

Keywords: fuel oil consumption; route planning; ISO 15016:2015; ship resistance and power

\section{Research Motivation}

The shipping industry utilizes $5 \%$ of the global crude oil consumption as bunker fuel in maritime transportation [1]. This amounts to four million barrels of fuel per day. Shipping companies have extended various efforts to reduce the fuel oil consumption from the designing to operation stages of a ship. Route planning significantly affects various efforts. This is because the fuel oil consumption of a ship differs drastically, depending on its route. Unlike vehicles that operate on the roads, ships operate on the water, and therefore, must overcome the limitations of the oceanic environment. Therefore, ships should be effectively operated considering safe transport and better control over economic issues. The oceanic environment, such as waves, winds, and current, exert additional resistance on the ship, and owing to this resistance, the efficiency of the ship varies between $50-80 \%$ [2]. The efficiency of the ship means that the difference in fuel consumption varies from $50 \%$ to $80 \%$ compared to the calm sea, depending on the oceanic environment. Therefore, various methods have been proposed to plan an economical route, while considering the resistance exerted by the oceanic environment. Ship route planning requires an accurate estimate of the fuel oil consumption of a ship operating in the oceanic environment. The estimation of fuel oil consumption is determined by the power of the main engine exerted by the additional resistance exerted by the hydro-meteorological conditions for oceans. Various methods are used to estimate the fuel oil consumption in ships. However, as the characteristics differ for each ocean, there has been a debate on which of the various estimation methods should be employed in ships. Therefore, in this study, a method for estimating the fuel oil consumption of ships under the oceanic environment was proposed based on ISO 15016:2015 [3] that is published by the International Organization for Standardization (ISO). 
In Section 2, various studies for estimating ship fuel consumption are compared and analyzed. Section 3 describes the purpose of ISO 15016 and a method for estimating the fuel consumption of a ship by using it. In Section 4, the results of the method proposed in this study are analyzed. Finally, Section 5 discusses the conclusions and future research plans.

\section{Literature Reviews}

Various studies have been estimating the fuel oil consumption of ships theoretically. The following is a literature survey on certain such studies.

Joo et al. [4] and Bang and Kwon [5] proposed a method for estimating the fuel oil consumption to plan an economically efficient route for a ship. They used the Townsin-Kwon method [6] to estimate the fuel oil consumption. Similarly, Lin et al. [7] and Vettor and Soares [8] conducted a study to optimize the shipping route. Unlike previous studies, they proposed a polynomial function for estimating the fuel oil consumption. Park et al. [9] proposed a second-order polynomial function to estimate the fuel oil consumption of a ship. The Townsin-Kwon method [6] and polynomial function are very simple to use as an estimation formula using the ship's main specifications and the oceanic environmental data. However, the methods have a disadvantage in that their accuracy is low depending on the type and shape of ships. Roh [10], Wei and Zhou [11], and Chen [12] studied weather routing and estimated the fuel oil consumption of ships based on the ISO 15016:2002 method [13]. When estimating the fuel consumption using ISO 15016:2002 [13], calculating additional resistance and estimating the power of a ship are outdated and do not reflect recently developed ships and accumulated operating data. As mentioned previously, various methods have been applied to estimate the fuel oil consumption of a ship. However, there are limitations in employing these methods in the practical operation of ships. Therefore, commercial programs for route planning developed their own methods for estimating fuel oil consumption. Eniram [14] is a representative route planning program that estimates the fuel oil consumption of ships using a statistical method based on the experience and operating data accumulated over several years. Samsung Heavy Industries (SHI) [15] developed an in-house program called EN-SAVER for ship owners. Furthermore, the SHI estimated the fuel oil consumption of a ship based on its in-house statistical methods. Furthermore, several other route planning programs $[16,17]$ are reported in the literature. However, an estimation model is generally not disclosed owing to confidentiality. The statistical method makes a model based on a lot of the operating data and is very accurate. However, there is a limit to the development of the model by academia or industry that does not have the operating data. As described earlier, several studies have been estimating the fuel oil consumption using different methods. In this study, the fuel oil consumption is estimated based on ISO 15016:2015 [3], which is improved ISO 15016:2002 [13] that was predominantly used in several previous studies. Table 1 summarizes the methods mentioned above.

Table 1. Summary of related studies and comparison with this study.

\begin{tabular}{ccc}
\hline Research & Method for Estimating Fuel Oil Consumption & Application \\
\hline Joo et al. [4] & Townsin-Kwon method & All ships \\
Bang and Kwon [5] & Townsin-Kwon method & All ships \\
Lin et al. [7] & Polynomial function & All ships \\
Vettor and Soares [8] & Polynomial function & All ships \\
Park et al. [9] & 2nd order polynomial function & All ships \\
Roh [10] & ISO 15016:2002 & All ships \\
Wei and Zhou [11] & ISO 15016:2002 & All ships \\
Chen [12] & ISO 15016:2002 & All ships \\
Eniram [14] & Statistical method & Specific ships \\
SHI [15] & Statistical method & Specific ships \\
This study & ISO 15016:2015 & All ships \\
\hline
\end{tabular}




\section{Evaluation of Speed and Fuel Consumption of Ship Using ISO 15016}

We proposed a method based on ISO 15016:2015 [3] to estimate the fuel oil consumption of a ship. ISO 15016 is "guidelines for the assessment of speed and power performance by analysis of speed trial data." In other words, it is a method of estimating the speed and power of a ship using sea trial data. Generally, the sea trial test is conducted when the oceanic environment is calm. Nevertheless, because of the nature of the sea, the environment cannot be the same as the condition set by the regulation of the Energy Efficiency Design Index (EEDI). The defined state refers to smooth hull and propeller surfaces, no wind, no wave, no current, and deep water of $15^{\circ} \mathrm{C}$. Therefore, to calculate the actual performance of a ship in the defined state as mentioned above, the reduced performance of the ship, which is caused by a resistance exerted by the oceanic environment, in the sea trial test should be estimated. The performance of the ship can be estimated in the state-regulated by the EEDI. The guideline used for this is ISO 15016. Figure 1 illustrates the purpose of using ISO 15016.

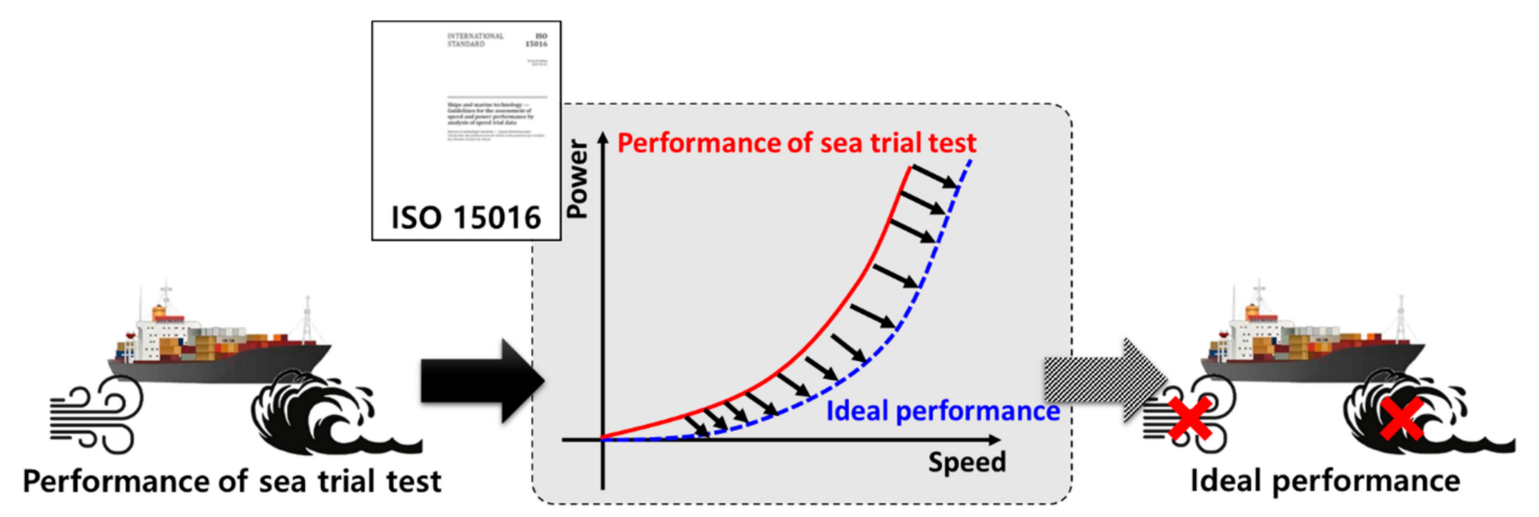

Figure 1. Purpose of ISO 15016.

On the other hand, to estimate the fuel oil consumption required for the operation of the ship, the reverse process of ISO 15016, which was previously described, should be implemented. In other words, the performance of the ship in the oceanic environment should be calculated using the ideal performance of the ship determined in the sea trial test. The additional resistance exerted by the oceanic environment is calculated, and the amount of performance degradation of the ship is calculated using the additional resistance. This process can be adapted in ISO 15016:2002 [13] and ISO 15016:2015 [3]. The difference between the two processes is explained below.

\subsection{ISO 15016:2002 for the Assessment of Speed and Power Performance}

A series of steps are involved in estimating the fuel oil consumption of the ship in the oceanic environment using ISO 15016:2002 [13]. First, the additional resistance on the ship exerted by the oceanic environment is calculated. The speed decelerated by the additional resistance is calculated. The main engine requires further increased power to compensate for the reduced speed. Hence, this power is calculated. Then, we calculate the fuel oil consumption required to produce the previously calculated power. This process is summarized in Figure 2. 


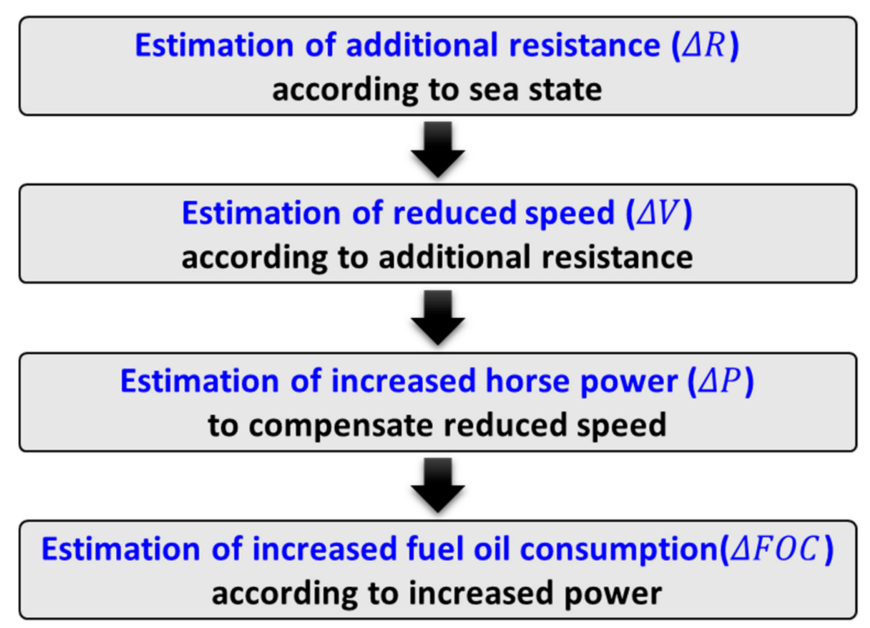

Figure 2. Process of estimation of fuel oil consumption using ISO 15016:2002.

According to ISO 15016:2002 [13], the additional resistance $\Delta R$ can be divided into six components. In other words, $\Delta R$ can be calculated by dividing it into resistance exerted by the oceanic wave, wind, steering gear, drift, water temperature, and density, and displacement. The resulting reduced ship's speed can be divided into four components-the amount of velocity reduced due to the oceanic wave, wind, current, and shallow water. They can be estimated using the additional resistance calculated previously. According to the ISO 15016:2002 [13], two methods are recommended for calculating the power required to compensate for the reduced speed: The formula proposed by Nakamura and Naito [18], and that proposed by Townsin and Kwon [6]. Thus, when the additional power $\triangle P$ required for the ship is calculated, the amount of fuel oil consumption $\triangle F O C$ additionally required for the ship can be obtained using the specific fuel oil consumption (SFOC) and estimated time of arrival (ETA), while considering the ship engine specifications. The details regarding the estimation of the fuel oil consumption of ships using the ISO 15016:2002 [13] are described by Roh [10].

However, the ISO 15016:2002 [13] is old and does not reflect the recent design or analysis trends that consider additional resistance. Moreover, the conventional ISO 15016:2002 has a variety of correction options when used. Thus, it is possible to derive different results of speed and fuel consumption depending on the engineer. Therefore, the method for analyzing the sea trial test was simplified and advanced by the International Towing Tank Conference (ITTC). Based on the revised ITTC guideline [19], ISO 15016 has also been revised. Therefore, in this study, a method to estimate the fuel oil consumption of a ship was proposed by reflecting on the revised guidelines.

\subsection{Method for the Estimation of Fuel Oil Consumption Using ISO 15016:2015}

The purpose of the ISO 15016 is to calculate the ideal performance using the results of the sea trial data of the ship. A summary of the process of ISO 15016:2015 [3] is shown in Figure 3. First, the additional resistance exerted by the oceanic environment is obtained. The power of the ship is obtained using additional resistance. Here, the direct power method (DPM) is used to calculate the power. The speed of the ship is corrected considering the current. Using the corrected speed and DPM, the power of the ship is further calculated. Finally, the speed of the ship is corrected using the current and shallow water effect. The power and speed of the ship are estimated as the final ideal performance. In addition, additional corrections can be calculated for various loading conditions.

In this study, the necessary steps in Figure 3 were used to estimate the fuel oil consumption of an operating ship. Thus, a process for estimating the fuel oil consumption of a ship is proposed using the known performance of the ship (ideal performance). Figure 4 summarizes the process based on ISO 15016:2015 [3] to estimate the fuel oil consumption of a ship. 


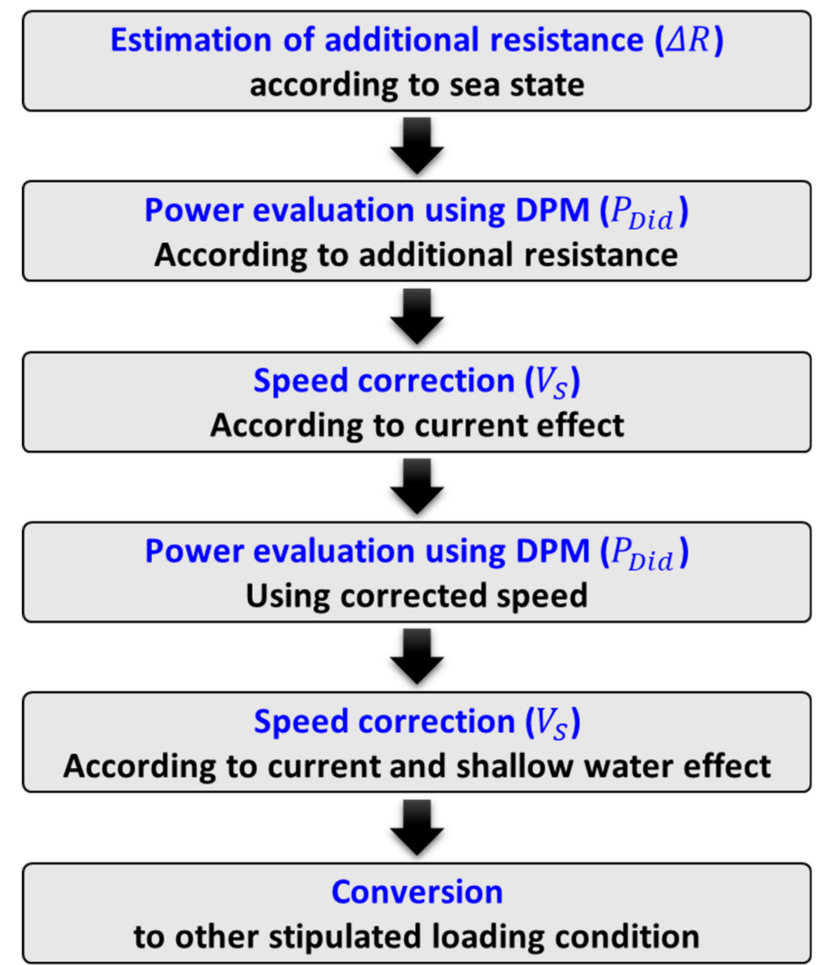

Figure 3. Process of ISO 15016:2015. DPM, direct power method.

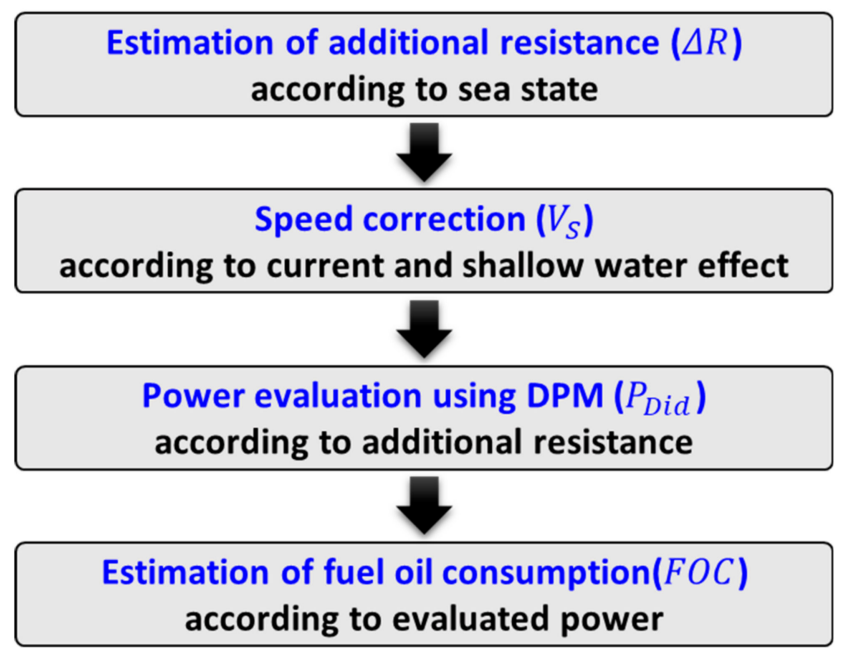

Figure 4. Process of the estimation of fuel oil consumption using ISO 15016:2015.

To estimate the fuel oil consumption of a ship using the ISO 15016:2015 [3], the additional resistance exerted by the oceanic environment is first calculated. Here, except for calculating the effect on current, it is directly used for speed correction. The ship's speed is calculated by considering the effect on the current and shallow water effect. As described previously, in the original ISO 15016:2015 [3], the speed correction process is performed twice. This is because it is difficult to measure the current when performing a sea trial test on the coast. Hence, the correction is performed twice to compensate for the difficulty. However, in the case of operating conditions where relatively accurate information can be obtained from weather centers, a single-speed correction suffices. Then, the power of the ship is calculated using the calculated additional resistance and corrected speed of the ship. In this process, the DPM is used for calculating the power and speed. Finally, the ship's fuel oil consumption can be estimated using the calculated speed and power. 
The proposed method based on ISO 15016:2015 [3] to estimate the fuel oil consumption of a ship is similar to the method described in Section 3.1. However, the proposed method further calculates the additional power required owing to the reduced speed because of the additional resistance. Furthermore, it calculates the power and corrected speed using the DPM.

\subsubsection{Estimation of Additional Resistance}

According to the ISO 15016:2015 [3], the additional resistance experienced by a ship during operation can be classified into three components. The ship's additional resistance $\Delta R$ can be calculated using Equation (1).

$$
\Delta R=R_{A A}+R_{A W}+R_{A S}
$$

where $R_{A A}$ is the additional resistance exerted by relative wind, $R_{A W}$ is the additional resistance exerted by waves, and $R_{A S}$ is the additional resistance exerted by water temperature and density.

Furthermore, the $R_{A A}$ can be calculated using Equation (2).

$$
R_{A A}=0.5 \rho_{A} \cdot C_{A A}\left(\psi_{\text {WRref }}\right) \cdot A_{X V} \cdot V_{W R r e f}^{2}-0.5 \rho_{A} \cdot C_{A A}(0) \cdot A_{X V} \cdot V_{G}^{2}
$$

where $A_{X V}$ is the transverse projected area above the waterline, $C_{A A}$ is the wind resistance coefficient, $V_{G}$ is the measured ship's speed over the ground, $V_{\text {WRref }}$ is the relative wind velocity at the reference height, $\psi_{W R r e f}$ is the relative wind direction at the reference height, and $\rho_{A}$ is the mass density of air. The wind resistance coefficient $\left(C_{A A}\right)$ is a function of the relative wind direction $\left(\psi_{\text {WRref }}\right)$. Therefore, $C_{A A}(0)$ means the value of $C_{A A}$ when the relative wind direction is ' 0 .' In principle, the $C_{A A}$, which is the coefficient of wind resistance, can be obtained through a wind tunnel test. However, STA-JIP [20] provides a dataset of wind resistance coefficients obtained through various experiments. The data provided by STA-JIP [20] contains various types of ships, such as tankers, LNG carriers, container ships, and car carriers. Figure 5 shows an example of a wind resistance coefficient provided by STA-JIP [20] for a 6800 TEU container ship.

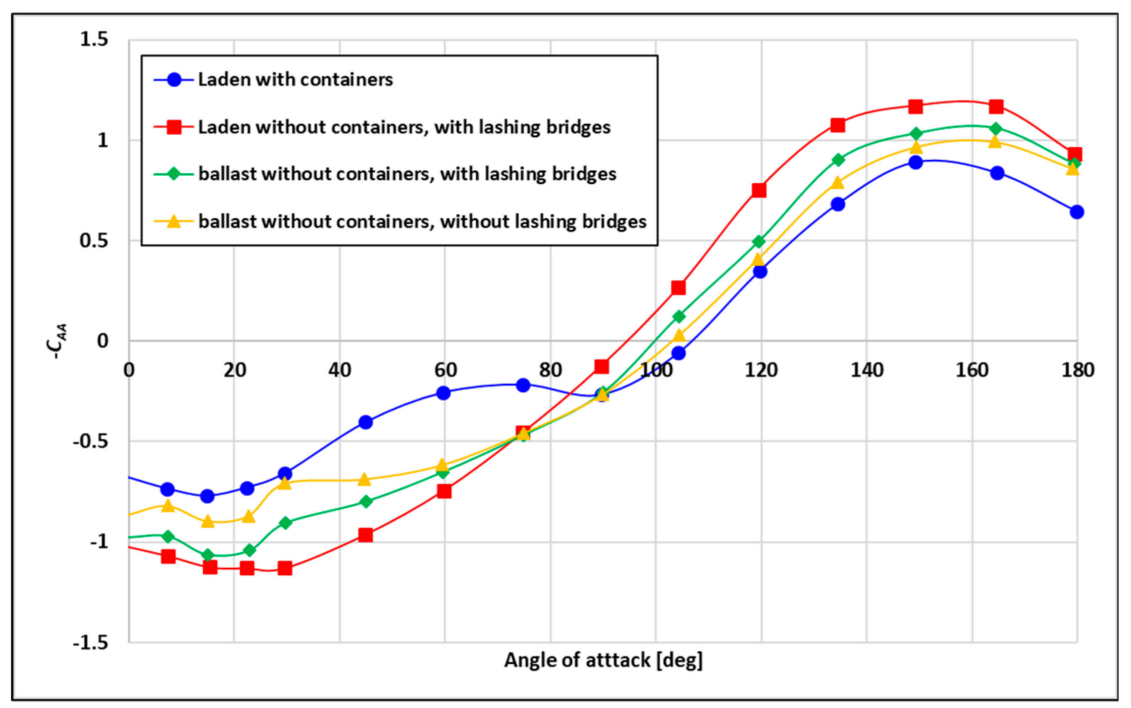

Figure 5. Wind resistance coefficient of the 6800 TEU container ship.

The ISO 15016:2015 [3] recommends that the additional resistance $R_{A W}$, exerted by the waves on the ship, should be obtained using four methods: STAWAVE-1, STAWAVE-2, theoretical method, and seakeeping model test. Among them, STAWAVE-1 is the simplest method that is mainly used in heading sea situations, where pitch and heave motion are small. In situations where prismatic coefficient $C_{P}$ and waterplane area coefficient $C_{W P}$ curves can be obtained, the theoretical method can be used. The most accurate method is to measure the additional resistance among waves using 
seakeeping tests. STAWAVE-1 has a limitation that it should be used solely in the heading sea under relatively moderate weather conditions. As mentioned previously, the theoretical method requires additional ship information. Furthermore, it is difficult to perform seakeeping tests without large-scale testing facilities. Therefore, in this study, the additional resistance in the waves was calculated using STAWAVE-2, which has few restrictions on its application and can be calculated with relatively less ship information. The STAWAVE-2 is an empirical method that approximates the additional resistance among waves exerted on a ship [20]. The empirical transfer function $R_{\text {wave }}$ can be calculated using Equation (3).

$$
R_{\text {wave }}=R_{A W M L}+R_{A W R L}
$$

where $R_{A W R L}$ is the mean resistance increase exerted by wave reflection, and $R_{A W M L}$ is the motion-induced resistance. The $R_{A W M L}$ and $R_{A W R L}$ can be obtained using Equations (4)-(6).

$$
\begin{gathered}
R_{A W M L}=4 \rho_{s} g \zeta_{A}^{2} \frac{B^{2}}{L_{P P}} \overline{r_{a w}}(\omega) \\
R_{A W R L}=\frac{1}{2} \rho_{s} g \zeta_{A}^{2} B \alpha_{1}(\omega) \\
R_{A W}=2 \int_{0}^{\infty} \frac{R_{\text {wave }}\left(\omega, V_{S}\right)}{\zeta_{A}^{2}} S_{\eta}(\omega) d \omega
\end{gathered}
$$

where $\rho_{s}$ is the water density, $g$ is the gravitational acceleration, $\zeta_{A}$ is the wave amplitude, $L_{P P}$ is the ship's length between perpendiculars, $B$ is the ship's breadth, $C_{B}$ is the block coefficient of the ship, $F r$ is the Froude number of the ship, $\omega$ is the circular frequency of regular waves, $k_{y y}$ is the non-dimensional radius of hydration in the lateral direction, $r_{a w}$ is the empirical formula needed to calculate the motion-induced resistance, which is a function of the circular frequency of regular waves $(\omega)$ [21], and $S_{\eta}$ is the frequency spectrum for wind-wave modified Pierson-Moskowitz type [22]. Then, the additional resistance of the wave $R_{A W}$ can be calculated using Equation (6) by integrating the mean resistance increase in a short-crested irregular wave within the wave frequency from 0 to $\infty$. The details of STAWAVE-2 are described in the study of van den Boom et al. [23].

Finally, the additional resistance to the temperature and density of seawater $R_{A S}$ is obtained when the ship does not operate under the EEDI regulation of $15^{\circ} \mathrm{C}$ and $1.026 \mathrm{~kg} / \mathrm{m}^{3}$, as described in Equations (7)-(9).

$$
\begin{gathered}
R_{A S}=R_{T 0}\left(\frac{\rho_{S}}{\rho_{S 0}}-1\right)-R_{F}\left(\frac{C_{F 0}}{C_{F}}-1\right) \\
R_{F}=\frac{1}{2} \rho_{S} S V_{S}^{2} C_{F} \\
R_{T 0}=\frac{1}{2} \rho_{S 0} S V_{S}^{2} C_{T 0}
\end{gathered}
$$

where $C_{F}$ is the frictional resistance coefficient for the actual water temperature and water density, $C_{F 0}$ is the frictional resistance coefficient for the reference water temperature and water density, $C_{T 0}$ is the total resistance coefficient for the reference water temperature and water density, $S$ is the wetted surface area, $\rho_{S}$ is the water density for the actual water temperature and salt content, and $\rho_{S 0}$ is the water density for the reference water temperature and salt content.

\subsubsection{Speed Correction for Current and Shallow Water Effects}

In Section 3.2.1, the additional resistance of the oceanic environment was calculated. Here, the additional resistance considers wind, wave, water temperature, and water density. Among the oceanic environment, the current and shallow water effects were not considered. In the ISO 15016:2015 [3], the 
current and shallow water effects are used to correct the speed of the ship. The ship's speed can be corrected using Equation (10).

$$
V_{S 1}=V_{G}-V_{C}
$$

As the ISO 15016:2015 [3] is based on the sea trial test, the current speed is corrected using the iterative method or the mean of means method. However, in this study, because the current speed is a value provided by the weather center, the current speed is used to correct the ship's speed, as shown in Equation (10).

The correction for the shallow water effect can be calculated using Equation (11).

$$
\frac{\Delta V}{V_{S 1}}=0.1242\left(\frac{A_{M}}{h^{2}}-0.05\right)+1-\left(\tanh \frac{g h}{V_{S 1}^{2}}\right)^{1 / 2} \text { for } \frac{A_{M}}{h^{2}} \geq 0.05
$$

where $\Delta V$ is the decrease in ship's speed (due to shallow water), $h$ is the water depth, $A_{M}$ is the midship section area under the waterline, $g$ is the acceleration (due to gravity), and $V_{S 1}$ is the corrected ship's speed through the water calculated according to Equation (10). As previously described, when the correction value $\Delta V$ is obtained by considering the current and shallow water effects, we can obtain the corrected ship's speed through the water using Equation (12).

$$
V_{S}=V_{S 1}-\Delta V
$$

\subsubsection{Power Evaluation Using the DPM}

Using the previously calculated additional resistance $\Delta R$ and corrected ship's speed $V_{S}$, the required power of the ship can be calculated. The ISO 15016:2015 [3] recommends a method for calculating the required power of a ship using the DPM. Various factors for the ship's performance (e.g., relative-rotative efficiency, thrust deduction fraction, thrust coefficients, etc.) are required to employ the DPM. In general, shipping companies or shipbuilding companies use measured or experimental values. However, in this study, because the DPM should be used in a situation where detailed information of ship is not available, the assumption or approximation methods were employed. Figure 6 summarizes the process of calculating the required power of a ship using the DPM.

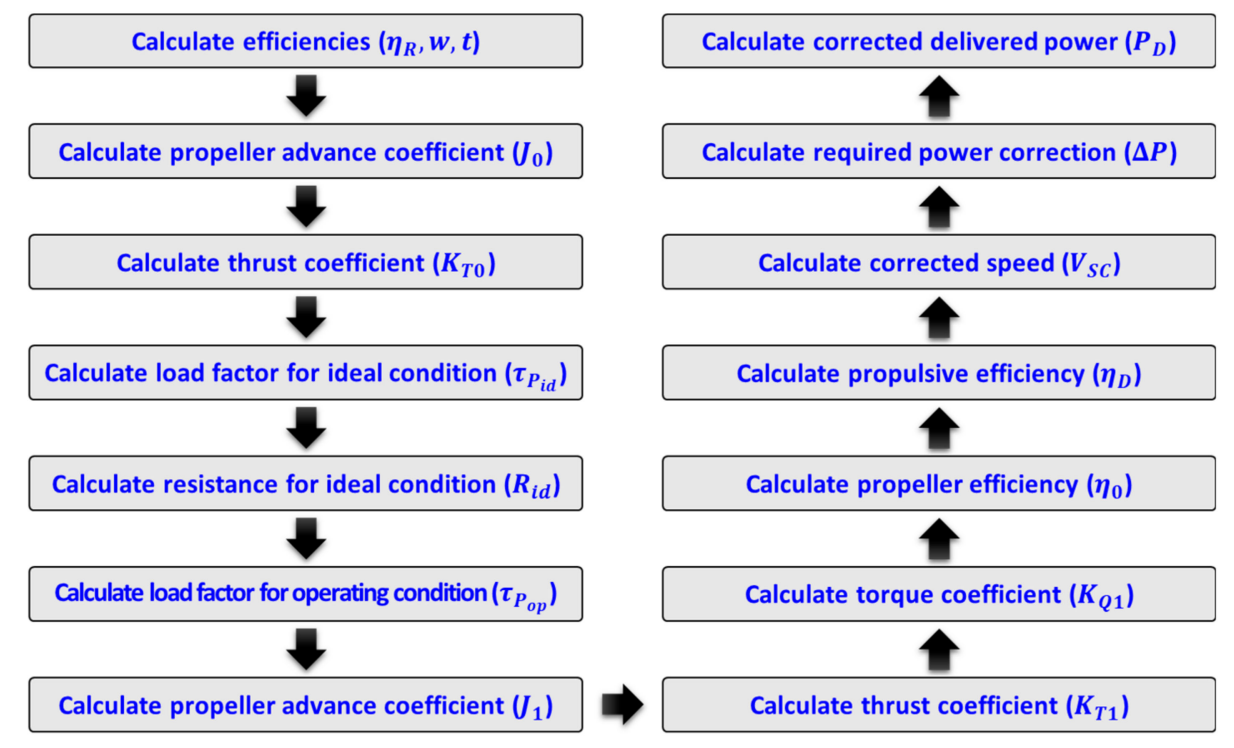

Figure 6. Process of power evaluation using DPM.

To employ the DPM, three propeller efficiencies of the ship should be identified. As described previously, the propeller efficiencies of the original ship are generally obtained through model 
experiments. However, in this study, the approximation formula proposed by Holtrop and Mennen [23] was used to calculate the three efficiencies: The relative-rotative efficiency $\eta_{R}$, thrust deduction fraction $t$, and wake fraction $w$. Using the calculated coefficient and Equation (13), we can calculate the propeller advance coefficient, $J_{0}$.

$$
J_{0}=\frac{V_{S}(1-w)}{n D_{p}}
$$

where $V_{S}$ is the ship's speed through the water that was calculated in Section 3.2.2, $n$ is the propeller shaft speed, and $D_{p}$ is the propeller diameter. The thrust coefficient $K_{T 0}$ can be expressed as Equation (14) using the propeller advance coefficient.

$$
K_{T 0}=a_{T 0} J_{0}^{2}+b_{T 0} J_{0}+c_{T 0}
$$

Equation (14) approximates the thrust coefficient to the quadratic equation of the propeller advance coefficient and is used to obtain the coefficients $a_{T 0}, b_{T 0}$, and $c_{T 0}$, which are used in further calculations. The thrust coefficient value is required to be calculated to obtain the aforementioned coefficients. In this study, the regression polynomial of the Wageningen B-series [24] was used to obtain the thrust coefficient value. The Wageningen B-series [24] approximates $K_{T}$ and $K_{Q}$ with a cubic equation for $J_{0}$. Because the quadratic equation of the thrust coefficient is required, three coefficients are obtained by re-approximating the cubic equation of the Wageningen B-series [24] to the quadratic equation using multiple regression. Then, the load factor $\tau_{\text {Pid }}$ for the ideal condition can be calculated as Equation (15) using the thrust coefficient.

$$
\tau_{P_{i d}}=\frac{K_{T 0}}{J_{0}^{2}}
$$

The resistance $R_{i d}$ for the ideal condition is calculated as Equation (16) using the calculated load factor.

$$
R_{i d}=\tau_{P_{i d}}(1-t)(1-w)^{2} \rho_{S} V_{S}^{2} D_{p}^{2}
$$

The load factor $\tau_{\text {Pop }}$ for the operating condition can be calculated as Equation (17) using the resistance for the ideal condition and additional resistance $\Delta R$ obtained in Section 3.2.1.

$$
\tau_{P_{o p}}=\frac{R_{i d}+\Delta R}{(1-t)(1-w)^{2} \rho_{S} V_{S}^{2} D_{p}^{2}}
$$

Subsequently, the propeller advance coefficient $J_{1}$ for the changed load factor is calculated as Equation (18).

$$
J_{1}=\frac{-b_{T 0}-\sqrt{b_{T 0}^{2}-4\left(a_{T 0}-\tau_{P_{o p}}\right) c_{T 0}}}{2\left(a_{T 0}-\tau_{P_{o p}}\right)}
$$

The coefficients $a_{T 0}, b_{T 0}$, and $c_{T 0}$, which are used in Equation (18), are the same as the coefficients approximated in Equation (14). Using the calculated propeller advance coefficient, the thrust coefficient $K_{T 1}$ and torque coefficient $K_{Q 1}$ are expressed as Equations (19) and (20).

$$
\begin{gathered}
K_{T 1}=a_{T 1} J_{1}^{2}+b_{T 1} J_{1}+c_{T 1} \\
K_{Q 1}=a_{Q 1} J_{1}^{2}+b_{Q 1} J_{1}+c_{Q 1}
\end{gathered}
$$

Similar to Equation (14), the values for the thrust coefficient and torque coefficient are first obtained using the regression polynomial of the Wageningen B-series [24], which is approximated to the cubic equation. Then, six coefficients $\left(a_{T 1}, b_{T 1}, c_{T 1}, a_{Q 1}, b_{Q 1}\right.$, and $\left.c_{Q 1}\right)$ are calculated using 
the re-approximated quadratic equations. The propeller efficiency $\eta_{O}$ for the operating condition is determined as Equation (21) using the calculated thrust and torque coefficients.

$$
\eta_{O}=\frac{J_{1}}{2 \pi} \frac{K_{T 1}}{K_{Q 1}}
$$

The propulsive efficiency $\eta_{D}$ can be calculated using Equation (22) using the calculated propeller efficiency.

$$
\eta_{D}=\eta_{O} \eta_{R} \frac{1-t}{1-w}
$$

where, $\eta_{R}$ is the relative-rotative efficiency, which can be calculated using the Holtrop and Mennen's approximation formula [23]. The changed speed $V_{S C}$ for the changed propulsive efficiency can be calculated as Equation (23).

$$
V_{S C}=\frac{n J_{1} D_{p}}{1-w}
$$

Then, using the changed speed and propulsive efficiency, the required power correction $\Delta P$ can be calculated as Equation (24).

$$
\Delta P=\frac{\Delta R V_{S C}}{\eta_{D}}
$$

Finally, the corrected delivered power $P_{D}$ (the power of the main engine) can be calculated using Equations (25) and (26).

$$
\begin{gathered}
P_{D}=P_{i d}+\Delta P \\
P_{i d}=R_{i d} V_{S}
\end{gathered}
$$

DPM does not use $\Delta P$ to compensate for the changed speed $\left(V_{S C}\right)$ to the design speed $\left(V_{S 1}\right)$. DPM is used to calculate the required power correction $(\Delta P)$ of the ship for the additional resistance $(\Delta R)$ as the ship proceeds using the changed speed $\left(V_{S C}\right)$ and the changed propulsive efficiency $\left(\eta_{D}\right)$. Therefore, assuming that the delivered power in ideal condition $\left(P_{i d}\right)$ is required to produce the design speed $\left(V_{S 1}\right)$, the changed speed $\left(V_{S C}\right)$ and the corrected delivered power $\left(P_{D}\right)$, due to the changed efficiencies, can be calculated simultaneously using DPM by considering the additional resistance $(\Delta R)$. If the control according to the engine control unit (ECU) compensates for the required power correction $(\Delta P)$ for the design speed $\left(V_{S 1}\right)$, the changed speed $\left(V_{S C}\right)$ should be the same as the design speed $\left(V_{S 1}\right)$. However, the compensated power is expected to increase fuel consumption.

\subsubsection{Estimation of Fuel Oil Consumption}

As mentioned in the previous section, using the DPM recommended in the ISO 15016:2015 [3], the delivered power $P_{D}$ required during the operation of a ship can be obtained using the information regarding the ideal condition of the ship. However, in general, the power of the main engine that is transmitted to the shaft of the ship is expressed as the break power $P_{B}$ (the power transmitted to the propeller); hence, we can calculate the break power as Equation (27).

$$
P_{B}=\frac{P_{D}}{\eta_{T}}
$$

where $\eta_{T}$ is the transmission efficiency. Then, we can obtain the information to calculate the fuel oil consumption of the ship. The fuel oil consumption FOC of the ship can be estimated using Equation (28).

$$
F O C=\operatorname{SFOC}(r p m) \cdot P_{D} \cdot \Delta t
$$

where $S F O C$ is the specific fuel oil consumption, which is determined by the specifications of the main engine, and it is expressed as a function of the main engine's RPM $(r p m)$. In addition, $\Delta t$ is the time at which the ship has operated at a specific rpm and can be calculated, as shown in Figure 7. In the figure, 
if the ship voyages from positions $P_{1}$ to $P_{2}$ with constant $r p m, \Delta t$ can be calculated using the distance $\Delta L$ traveled by the ship and corrected speed calculated in Section 3.2.3.

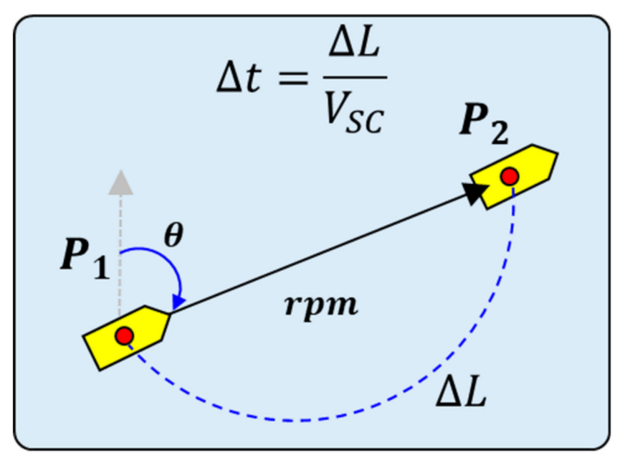

Figure 7. Calculation of $\Delta t$ using the corrected speed $V_{S C}$.

\section{Application}

To verify the applicability of the proposed method based on ISO 15016:2015 [3] for estimating the fuel oil consumption of a ship, the method was applied to a 4600 TEU container ship. This ship transports cargo between South Korea and the United States across the Pacific Ocean. The principal particulars of the ship are listed in Table 2.

Table 2. Principal particulars of the container ship.

\begin{tabular}{cc}
\hline Particulars & Value \\
\hline Length between perpendiculars & $237 \mathrm{~m}$ \\
Breadth & $37.5 \mathrm{~m}$ \\
Depth & $22 \mathrm{~m}$ \\
Draft & $11 \mathrm{~m}$ \\
Deadweight & $59,000 \mathrm{ton}$ \\
RPM at NCR & $77 \mathrm{rpm}$ \\
\hline
\end{tabular}

To confirm the accuracy of the proposed method, we compared it with the gray box model, which was modeled using actual operation data of the 4600 TEU container ship. The gray box model was generated by obtaining approximately 30,000 measured data from the ship's operation from March to July 2014. The error rate of the measured value was less than $0.5 \%$ for BHP, speed of the ship through the water, and FOC. The gray box model is a model that combines partial theoretical structure and data [25]. In general, a gray box model is created by adding coefficients referring to real data to an equation known as existing knowledge. The process of estimating the fuel oil consumption of the ship using the gray box model is shown in Figure 8.

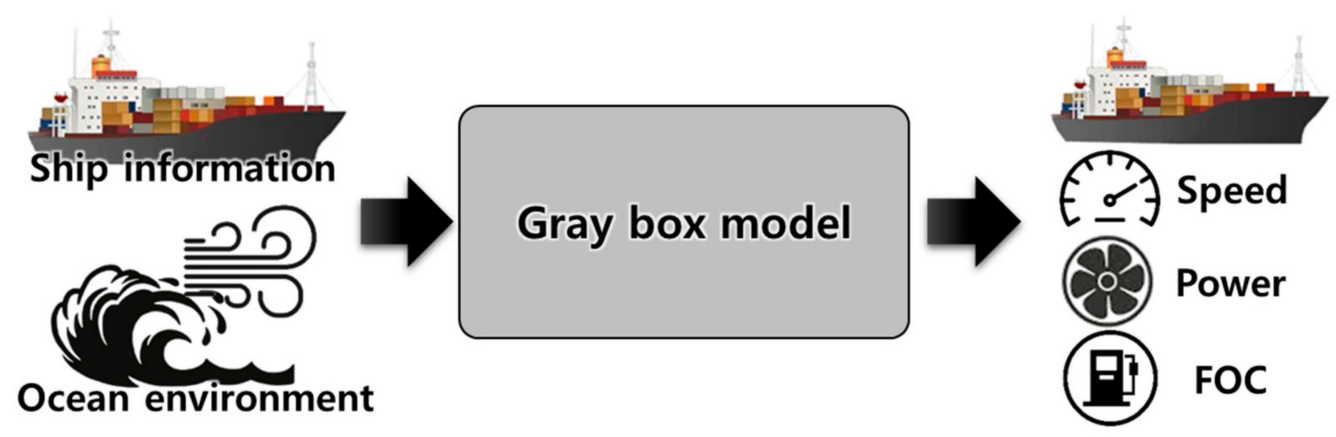

Figure 8. Input and output of the gray box model.FOC, fuel oil consumption. 
The oceanic environmental data used for the application were obtained from the National Oceanic and Atmospheric Administration (NOAA). The accessed data for the Pacific Ocean includes $3 \mathrm{~h}$ of data at an interval of $1^{\circ}$ in longitude and latitude. The data for five months (from February 2014 to June 2014) were accessed and used for the application.

\subsection{Case Definition}

The accuracy of the method based on ISO 15016:2015 [3] for measuring fuel oil consumption of ships was compared with that of the gray box model, and the comparison was performed using seven case studies. The route for all cases is from the Port of Busan in South Korea to the Port of Long Beach in the USA. The target route of the seven cases is similar to the great circle line, and the details of the route and waypoints are shown in Figure 9. The ship departed from the Port of Busan and passed through the Tsugaru Strait in Japan. Later, the ship crossed the Pacific Ocean and reached the Port of Long Beach. The total length of the route is 5247 NM, and in general, a ship is known to operate on the route over, approximately, 15 days.

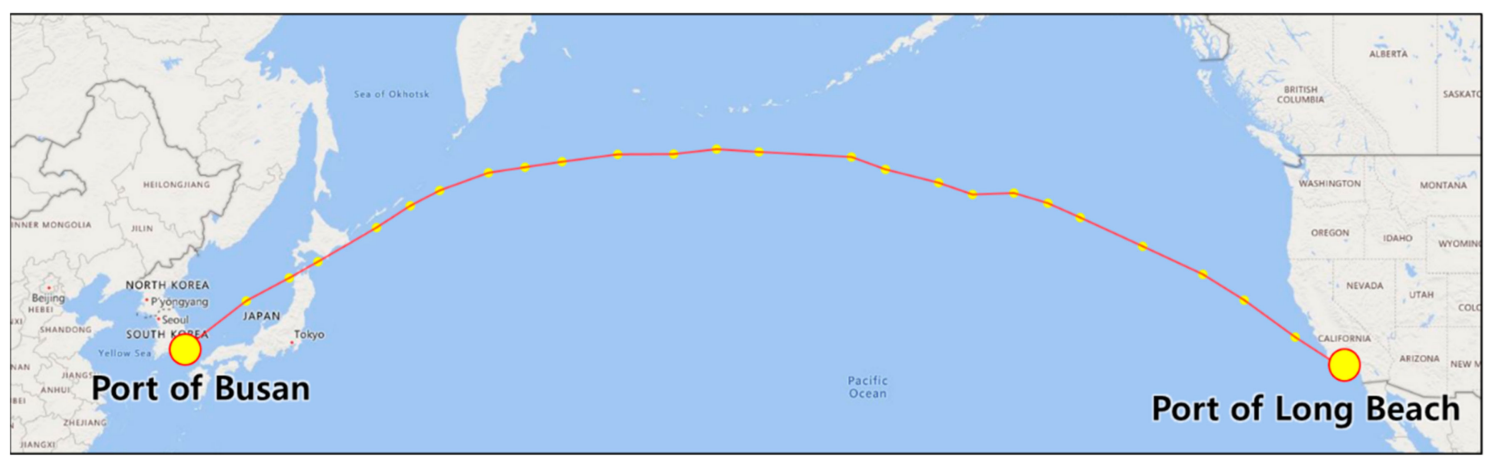

Figure 9. Ship route for application.

Cases 1, 2, and 3 compared the fuel oil consumption when the ship was operating in normal steaming. In Case 1, the ship's departure was on 3 March 2014, and the weather in the Pacific Ocean during this period was relatively bad. In Case 2, the ship's departure was on 8 April 2014, and the weather was moderate. In Case 3, the ship's departure was on 1 June 2014, and the weather in the Pacific Ocean was relatively good during this period. In Cases 1, 2, and 3, the accuracy of the proposed method was compared according to the three weather conditions in normal steaming.

Cases 4 and 5 compared the fuel oil consumption when the ship was operating in slow steaming. In Cases 4 and 5, the ship's departure was on 3 March 2014 and 1 June 2014, respectively. In the two cases, the accuracy of the proposed method was compared according to two weather conditions in slow steaming.

Cases 6 and 7 departed on the same date as Cases 4 and 5, but the ship was in fast steaming. Therefore, for Cases 6 and 7, the accuracy of the proposed method was compared according to two weather conditions in fast steaming. Table 3 summarizes the information from the cases.

Table 3. Summary of cases for the application.

\begin{tabular}{|c|c|c|c|c|c|}
\hline Cases & Departure & Arrival & Departure Date & Engine RPM & Weather Condition \\
\hline Case 1 & \multirow{7}{*}{$\begin{array}{l}\text { Port of Busan, } \\
\text { South Korea }\end{array}$} & \multirow{7}{*}{$\begin{array}{c}\text { Port of Long } \\
\text { Beach, USA }\end{array}$} & 3 March $2014,18: 00$ & \multirow{3}{*}{$\begin{array}{c}77 \\
\text { (normal } \\
\text { steaming) }\end{array}$} & Bad \\
\hline Case 2 & & & 8 April 2014, 18:00 & & Moderate \\
\hline Case 3 & & & 1 June 2014, 18:00 & & Good \\
\hline Case 4 & & & 3 March 2014, 18:00 & \multirow{2}{*}{$\begin{array}{c}55 \\
\text { (slow steaming) }\end{array}$} & Bad \\
\hline Case 5 & & & 1 June $2014,18: 00$ & & Good \\
\hline Case 6 & & & 3 March 2014, 18:00 & \multirow{2}{*}{$\begin{array}{c}90 \\
\text { (fast steaming) }\end{array}$} & Bad \\
\hline Case 7 & & & 1 June $2014,18: 00$ & & Good \\
\hline
\end{tabular}


As the weather changes from time to time, it is difficult to specify the oceanic environment for cases; hence, representative weather maps for weather passing in cases are presented as Figure 10.

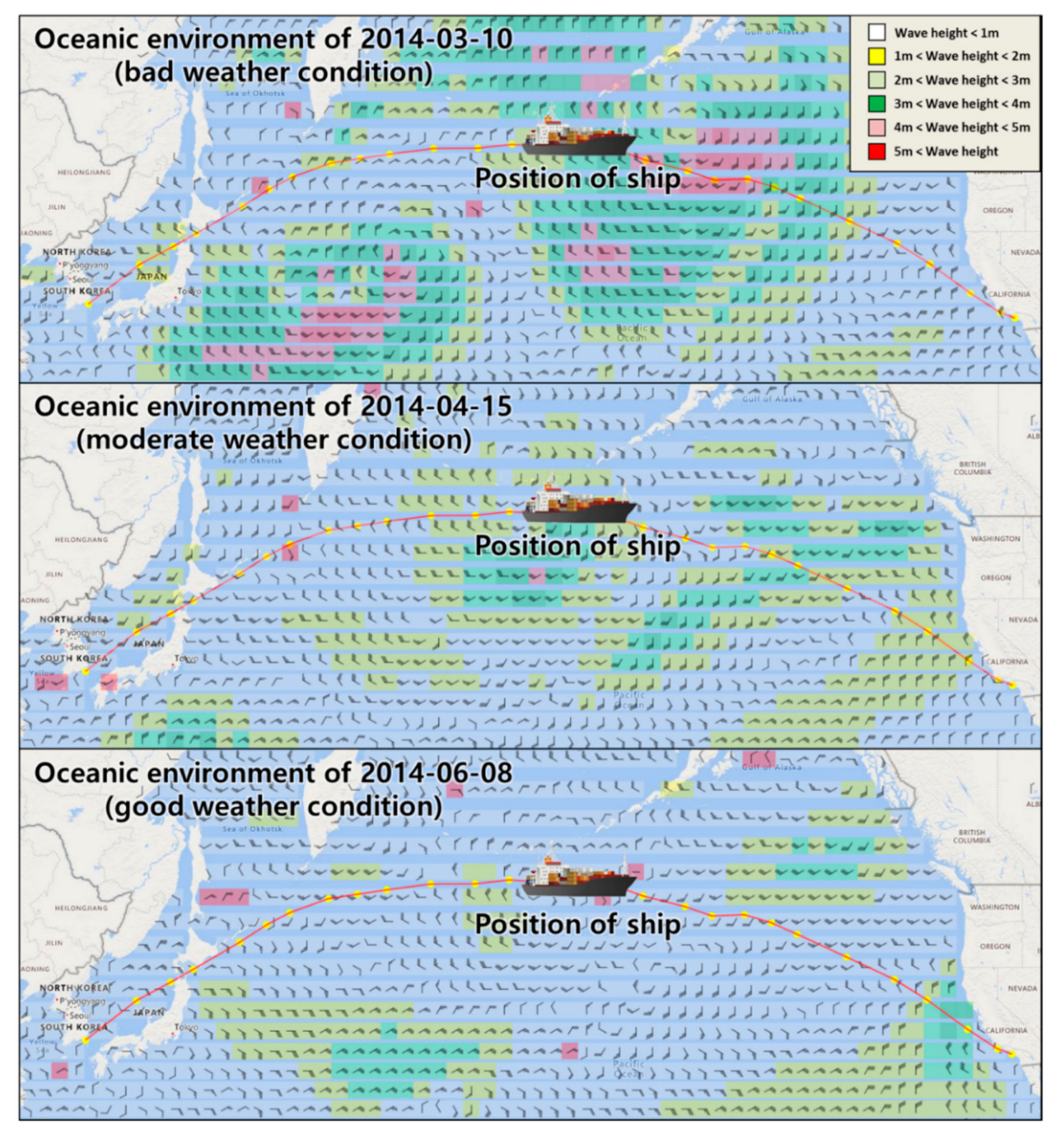

Figure 10. The representative oceanic environment of cases.

\subsection{Case Studies}

For the seven cases described in Table 3, the results of the total fuel oil consumption (TFOC) and average speed obtained using the gray box model and proposed method were compared. Table 4 shows the results of each case.

Table 4. Summary of results of total fuel oil consumption (TFOC) and average speed.

\begin{tabular}{|c|c|c|c|c|c|}
\hline Cases & Methods & TFOC (ton) & Average Speed (knot) & Arrival Time & Engine RPM \\
\hline \multirow{2}{*}{ Case 1} & Gray box model & $721.4(100 \%)$ & $17.47(100 \%)$ & 16 March 2014, 06:25 & \multirow{6}{*}{$\begin{array}{c}77 \\
\text { (normal } \\
\text { steaming) }\end{array}$} \\
\hline & ISO 15016:2015 & $694.3(96.2 \%)$ & $17.35(99.3 \%)$ & 16 March 2014, 08:24 & \\
\hline \multirow{2}{*}{ Case 2} & Gray box model & $692.4(100 \%)$ & $17.73(100 \%)$ & 21 April 2014, 01:56 & \\
\hline & ISO 15016:2015 & $685.9(99.1 \%)$ & $17.56(99.0 \%)$ & 21 April 2014, 04:47 & \\
\hline \multirow{2}{*}{ Case 3} & Gray box model & $674.0(100 \%)$ & $17.91(100 \%)$ & 13 June 2014, 22:56 & \\
\hline & ISO 15016:2015 & $685.9(101.8 \%)$ & $17.56(98.0 \%)$ & 14 June 2014, 04:46 & \\
\hline \multirow{2}{*}{ Case 4} & Gray box model & $418.3(100 \%)$ & $12.20(100 \%)$ & 21 March $2014,16: 03$ & \multirow{4}{*}{$\begin{array}{c}55 \\
\text { (slow steaming) }\end{array}$} \\
\hline & ISO 15016:2015 & $381.7(91.3 \%)$ & $12.20(100.0 \%)$ & 21 March 2014, 16:11 & \\
\hline \multirow{2}{*}{ Case 5} & Gray box model & $381.7(100 \%)$ & $12.44(100 \%)$ & 19 June 2014, 07:48 & \\
\hline & ISO 15016:2015 & $382.2(100.1 \%)$ & $12.18(97.9 \%)$ & 19 June $2014,16: 43$ & \\
\hline \multirow{2}{*}{ Case 6} & Gray box model & $949.4(100 \%)$ & $20.64(100 \%)$ & 14 March 2014, 08:12 & \multirow{4}{*}{$\begin{array}{c}90 \\
\text { (fast steaming) }\end{array}$} \\
\hline & ISO 15016:2015 & $916.6(96.5 \%)$ & $20.53(99.4 \%)$ & 14 March 2014, 09:38 & \\
\hline \multirow{3}{*}{ Case 7} & Gray box model & $898.5(100 \%)$ & $21.12(100 \%)$ & 12 June 2014, 02:29 & \\
\hline & ISO 15016:2015 & $906.6(100.9 \%)$ & $20.75(98.2 \%)$ & 12 June 2014, 06:50 & \\
\hline & Average ratio & $97.9 \%$ & $98.9 \%$ & & \\
\hline
\end{tabular}


As a result of comparing the results, the average speed of the proposed method was estimated to be slightly lower in all cases. In addition, when operating in bad weather conditions, the fuel oil consumption of the proposed method was estimated to be low when compared with the estimation of the gray box model. When the ship is operating in good weather conditions, the fuel oil consumption of the proposed method was slightly higher than that of the gray box model. For a precise comparison, the FOC, speed, and additional resistance graphs of the results obtained using the gray box model and proposed method for each case were compared. In all the cases, the additional resistance, due to water temperature and density, was insignificant, and hence, was excluded from the comparison.

Figure 11 shows the FOC, speed, and additional resistance graphs of Cases 1, 2, and 3. Case 1 has a considerable variation in the speed graph because it operated in bad weather conditions. As shown in the additional resistance graph, the additional resistance increases owing to high waves and strong winds, resulting in a large decrease in speed. As the time to travel the same distance varies owing to the difference in speed, it can be observed that the FOC of the proposed method is generally lower than that of the gray box model. As observed in the speed graph of Case 1, there are high fluctuations in the early and middle-parts of the route. This is possible because of the additional wind resistance observed in the additional resistance graph. In other words, the proposed method considers the influence of wind more than it is considered in the gray box model. Particularly, when the wind blows from the tail of the ship, an additional negative resistance occurs, and the speed of the ship increases owing to the additional negative wind resistance. In Case 3, where the weather is relatively good, the wind resistance is reflected significantly, resulting in a difference in speed. This induces a difference in the FOC.

Figure 12 shows the FOC, speed, and additional resistance graphs for Cases 4 and 5. In Cases 4 and 5, the overall speed and fuel oil consumption are small owing to slow steaming. In Case 4, the ship operated in bad weather conditions and departed on the same date as that in Case 1. However, the speed of the ship is slower, and the additional resistance is much smaller. Similar to Case 1, the speed of the ship is significantly affected by the wind, and the speed increases with the wind from the middle part of the route. In Case 5, the weather condition is relatively good; hence, the influence on the additional resistance is reduced, and the trend of the FOC and speed graphs is similar to those in the gray box model.

Figure 13 shows the FOC, speed, and additional resistance graphs for Cases 6 and 7. Cases 6 and 7 show that the ship's overall speed and fuel oil consumption are high owing to fast steaming. In Case 6, the ship operated in bad weather conditions and departed on the same date as that in Case 1. However, the speed of the ship is faster, and the additional resistance exerted on the ship is much greater. When the speed of the ship is high, the influence of the additional resistance that the ship experiences (owing to the increase in wave and influence of the wind, which was considered relatively high in the previous cases) are reduced. In Case 7, the weather condition is relatively good; hence, the influence on the additional resistance is reduced, and the trend of the FOC and speed graphs is similar to those in the gray box model. This is further observed when the ship is faster. 


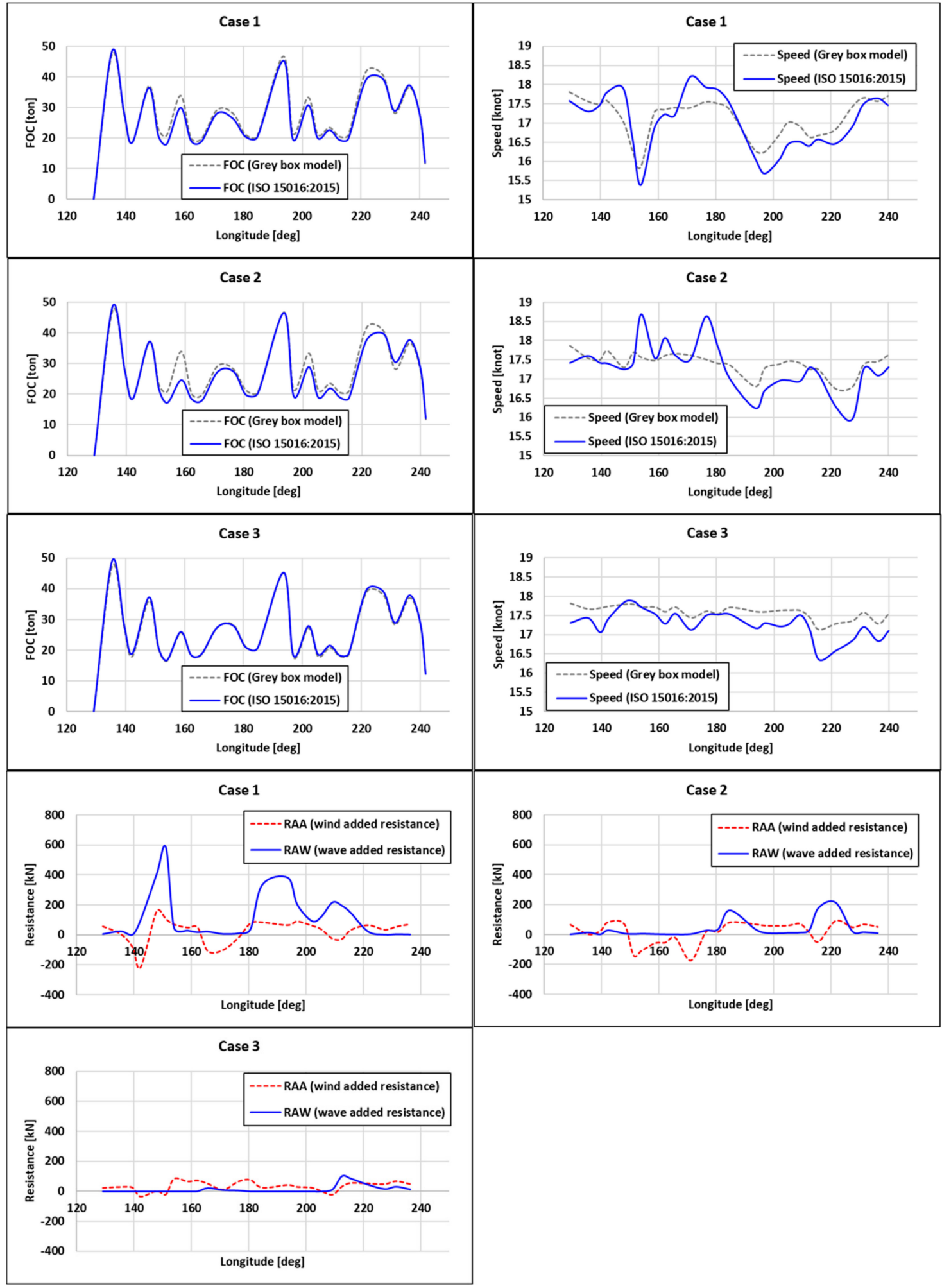

Figure 11. FOC, speed, and additional resistance graphs of Cases 1, 2, and 3. 


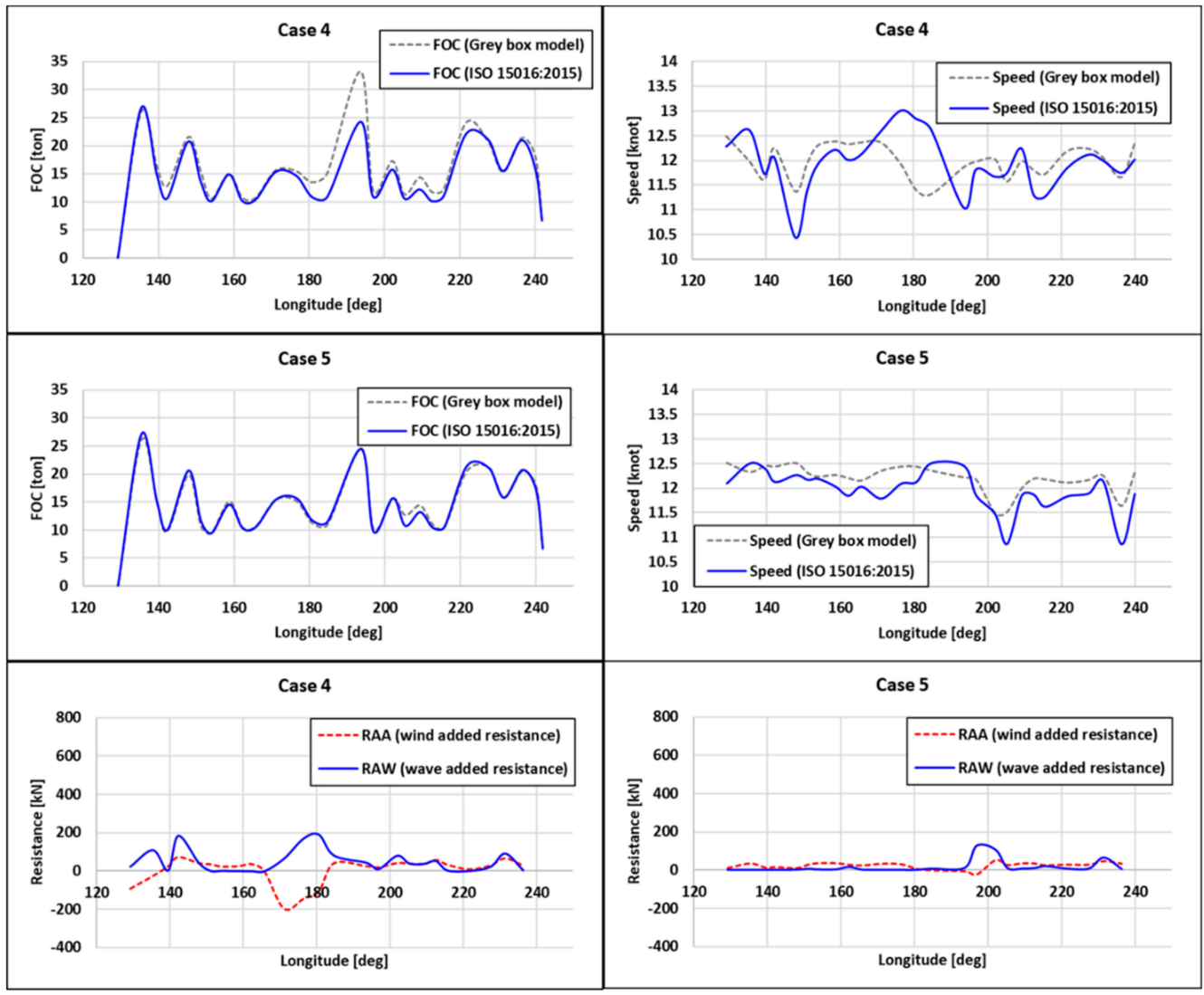

Figure 12. FOC, speed, and additional resistance graphs of Cases 4 and 5.

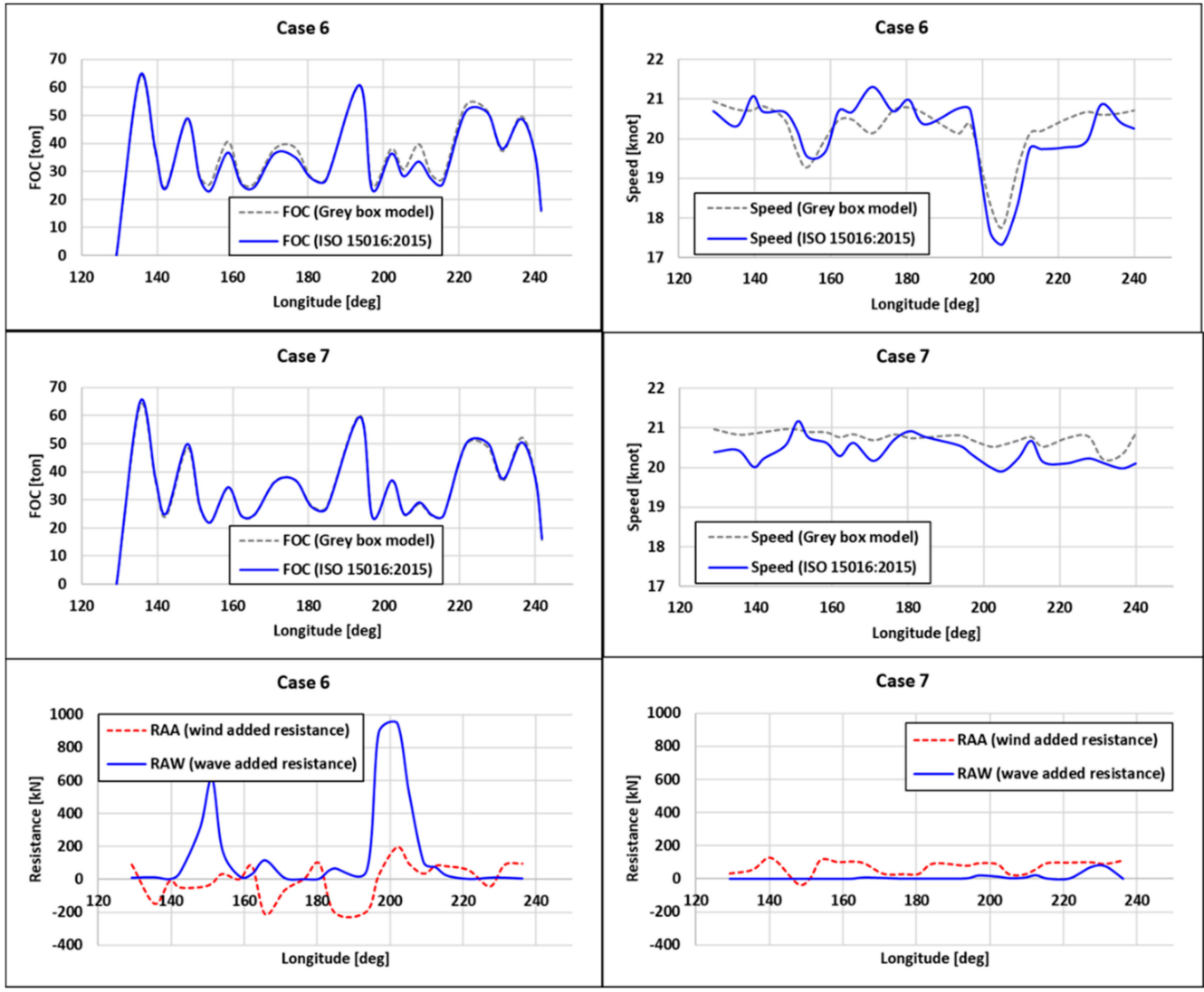

Figure 13. FOC, speed, and additional resistance graphs of Cases 6 and 7. 


\section{Conclusions and Future Work}

Estimating the fuel oil consumption of a ship is essential in ship route planning. To date, various methods have been used for the estimation. However, in general, ship information, such as hull form and model experiment information, is required for an accurate estimation. This information can solely be obtained by the ship in-charge and is difficult to access. Moreover, this study was conducted to improve the process for estimating the fuel consumption of the ship using the conventional ISO 15016:2002 [13]. To more accurately and simply estimate the fuel consumption of the ship, a method of estimating the fuel consumption of the ship was proposed by applying and modifying the ISO 15016:2015 [3]. The proposed method estimates with ease the fuel oil consumption using the conventional specifications of the ship. Therefore, it can be useful to employ the proposed method for the route planning of various ships.

In this study, the accuracy of the proposed method was compared with that of the gray box model, which employs operation data. The results estimated the fuel oil consumption and speed to be $3.1 \%$ (on average) and $2.1 \%$ lower than that of the gray box model, respectively. Particularly, during a bad weather condition, the error was relatively large, which is expected because the proposed method significantly considers the influence of wind. However, during good weather conditions, the results were similar to that of the gray box model. As discussed in Section 3.2, the ISO 15016:2015 is a method for estimating the performance of a ship under ideal conditions using sea trial data. As the sea trial test is mainly conducted in good weather, the accuracy is estimated to be higher when the influence of wind and waves is small.

To improve the accuracy of the proposed method, in the future, we will develop a method to calculate the additional resistance, while considering various operating conditions. In addition, we will review the effectiveness of the proposed method through further applications in various types of ships.

Author Contributions: Conceptualization, K.-S.K. and M.-I.R.; methodology, K.-S.K. and M.-I.R.; software, K.-S.K.; validation, K.-S.K. and M.-I.R.; formal analysis, K.-S.K. and M.-I.R.; investigation, K.-S.K.; resources, M.-I.R.; data curation, K.-S.K.; writing — original draft preparation, K.-S.K.; writing—review and editing, M.-I.R.; visualization, K.-S.K.; supervision, M.-I.R.; project administration, M.-I.R.; funding acquisition, M.-I.R. All authors have read and agreed to the published version of the manuscript.

Funding: This work was partially supported by (a) Research Institute of Marine Systems Engineering of Seoul National University, Korea and (b) Institute of Engineering Research of Seoul National University, Korea.

Conflicts of Interest: The authors declare no conflict of interest. The funders had no role in the design of the study; in the collection, analyses, or interpretation of data; in the writing of the manuscript, or in the decision to publish the results.

\section{References}

1. Avgouleas, K.; Sclavounos, P.D. Fuel-Efficient Ship Routing. Nat. Sci. Math. 2014, 5, 39-72.

2. Weber, T. The Importance of Weather Routing in Fuel-Efficient Shipping; Vessel Performance Optimization (VPO): London, UK, 2018.

3. ISO. ISO 15016:2015-Ship and Marine Technology-Guidelines for the Assessment of Speed and Power Performance by Analysis of Speed Trial Data; ISO: Geneva, Switzerland, 2015.

4. Joo, S.-Y.; Cho, T.-J.; Cha, J.-M.; Yang, J.-H.; Kwon, Y.-K. An Economic Ship Routing System Based on a Minimal Dynamic-cost Path Search Algorithm. KIPS Trans. Comput. Commun. Syst. 2012, 1, 79-86. [CrossRef]

5. Bang, S.-H.; Kwon, Y.-K. Economic Ship Routing System by a Path Search Algorithm Based on an Evolutionary Strategy. J. Korean Inst. Commun. Inf. Sci. 2014, 39, 767-773. [CrossRef]

6. Townsin, R.L.; Kwon, Y.J. Estimating the Influence of Weather on Ship Performance; Wind Press: Milano, Italy, 1993; Volume 135, pp. 191-209.

7. Lin, Y.-H.; Fang, M.-C.; Yeung, R.W. The optimization of ship weather-routing algorithm based on the composite influence of multi-dynamic elements. Appl. Ocean Res. 2013, 43, 184-194. [CrossRef]

8. Vettor, R.; Soares, C.G. Development of a ship weather routing system. Ocean Eng. 2016, 123, 1-14. [CrossRef] 
9. Park, J.; Kim, N. Two-Phase Approach to Optimal Weather Routing Using Real-Time Adaptive A* Algorithm and Geometric Programming. J. Ocean Eng. Technol. 2015, 29, 263-269. [CrossRef]

10. Roh, M.-I. Determination of an economical shipping route considering the effects of sea state for lower fuel consumption. Int. J. Nav. Arch. Ocean Eng. 2013, 5, 246-262. [CrossRef]

11. Wei, S.; Zhou, P. Development of a 3D Dynamic Programming Method for Weather Routing. In Methods and Algorithms in Navigation: Marine Navigation and Safety of Sea Transportation; CRC Press: Boca Raton, FL, USA, 2011; Volume 6, pp. 181-187. [CrossRef]

12. Chen, H. Voyage Optimization Supersedes Weather Routing; Jeppesen Marine Inc.: Denver, CO, USA, 2011; pp. 1-11.

13. ISO. ISO 15016:2002-Ship and Marine Technology_Guidelines for the Assessment of Speed and Power Performance by Analysis of Speed Trial Data; ISO: Geneva, Switzerland, 2002.

14. Eniram. Fuel Saving; Eniram: Helsinki, Finland, 2008.

15. Samsung. Samsung Heavy Industries Energy Efficiency Management System; Samsung: Seoul, Korea, 2017.

16. Schlinkert, G. StormGeo Route Planning for Different Ship Types and Speeds; StormGeo: Bergen, Norway, 2019.

17. SeaRates. DP World SeaRates Route Planner; SeaRates: Dubai, UAE, 2020.

18. Nakamura, S.; Naito, S. Nominal speed loss and propulsive performance of a ship in waves. J. Soc. Nav. Archit. Kansai 1972, 166, 25-34.

19. ITTC. ITTC Recommended Procedures and Guidelines, Analysis of Speed/Power Trial Data. 7.5-04-01-01.2; ITTC: Nantes, France, 2014.

20. Sea Trial Analysis JIP. Recommended Analysis of Speed Trials; MARIN: Wageningen, The Netherlands, 2006.

21. Van den Boom, H.; Huisman, H.; Mennen, F. New Guidelines for Speed/Power Trials: Level Playing Field Established for IMO EEDI; SWZ/Maritime: Rotterdam, The Netherlands, 2013; pp. 1-11.

22. Stewart, R.H. Chapter 16-Ocean Waves. In Introduction to Physical Oceanography; Texas A\&M University: College Station, TX, USA, 2008.

23. Holtrop, J.; Mennen, G. An approximate power prediction method. Int. Shipbuild. Prog. 1982, $29,166-170$. [CrossRef]

24. Bernitsas, M.M.; Ray, D.; Kinley, P. Kt, Kq and Efficiency Curves for the Wageningen B-Series Propellers; The University of Michigan: Ann Arbor, MI, USA, 1981.

25. Kroll, A. Grey-box models: Concept and application. In New Frontiers in Computational Intelligence and Its Application; IOS Press: Amsterdam, The Netherlands, 2000; Volume 57, pp. 42-51. 